\title{
POTABLE WATER DEFLUORIDATION BY LOWCOST ADSORBENTS FROM MIMOSIDEAE FAMILY FRUIT CARBONS: A COMPARATIVE STUDY
}

\author{
KISHORE MEDIKONDU \\ SVRM College Nagaram (Autonomous), Andhra Pradesh., India \\ Email:drmedikondukishore@gmail.com
}

Keywords: Activated carbons; Fluoride; Adsorption; Kinetics; Recycling; Regeneration; comparative study

\begin{abstract}
Fluoride present in the form of minerals, which dissolves in ground water and contaminates it. This paper deals with the mimosideae family fruit carbons are used for the removal of fluoride by the process of adsorption. The activated carbon was prepared by carbonisation of Enterolobium saman fruit carbon (ESC) and Prosofis juliflora fruit carbon (PJC) in muffle furnace and treated with $2.5 \times 10^{-1} \mathrm{M}$ nitric acid and thermally activated in air oven. The activated carbon was characterized and chemical analysis was done by X-ray fluorescence. Batch experiments were carried out to establish the various parameters. The adsorption was examined by studying the impact of various parameters such as 1) initial concentration $(1-7 \mathrm{mg} / \mathrm{L})$. Maximum $(76-82 \%)$ removal fluoride concentration up to $5 \mathrm{mg} / \mathrm{L}$ after this the removal percentage was low. 2) $\mathrm{pH}(5-9)$ higher removal percentages in neutral media. 3) Dose $(1-7 \mathrm{mg} / \mathrm{L})$. After $4 \mathrm{mg} / \mathrm{L}$ removal adsorption capacity was very low 4) time (10 $\mathrm{min}-90 \mathrm{~min})$. Maximum adsorption was observed between $40-$ $60 \mathrm{~min}$. and 5) Particle size $(45 \mu-150 \mu) 45 \mu$ sized carbon shows higher adsorption capacity (90.8 $\%, 80.2 \%$ for ESC and PJC). Recycling studies and regeneration of the fluoride loaded carbons were performed with $1.0 \times 10^{-1} \mathrm{NaOH} \mathrm{mol} / \mathrm{l}(72 \%), \mathrm{Na}_{2} \mathrm{CO}_{3}, \mathrm{KOH}$ and $1.0 \times 10^{-2} \mathrm{H}_{2} \mathrm{SO}_{4} \mathrm{~mol} / 1$ solutions (68-58\%). Adsorption data fits well to Langmuir isotherm and Freundlich isotherms and sorption kinetics Natarajan \& Khalaf, intra particle diffusion model follows first order nature of adsorption. All experimental results were compared with the studies of commercial activated carbon (CAC) and comparative results indicate ESC and PJC shows 3 to 4 times higher adsorption capacity than CAC.
\end{abstract}

\section{INTRODUCTION}

Water is essential for the man land which keeps life going. But now a day's pure water is available to very few people. Else take more or less contaminated water. This water may be contaminated by number of ways. On such contaminants fluoride is very important one. The presence of fluoride more than $1.5 \mathrm{mg} / \mathrm{L}$ will cause health hazards. Regular consumption of this will cause dental fluorosis, skeletal fluorosis, early cataract formation and non skeletal fluorosis like and causes in number of deficiencies. So it was an environmental issue and it needs to minimise to desirable limits. Thus defluoridation becomes necessary.

In search of a viable method for the removal of fluoride in drinking water several applications have reportedly achieved promising results and keen observation of literature survey it was found that different natural and synthetic materials have been developed for defluoridation such as wood, lignite, coal, bone char, nut shells, paddy husk, avaram bark, coffee husk, tea waste, jute waste, coconut shell, coir pith, fly ash, carbon, serpentine, alum and lime (Nalgonda technique), Clay minerals, Fish bone, Calcite, Eichhornia sp. (water hyacinth) biomass, activated charcoal, neem leaves carbon, straw carbon, rice husk carbon, coconut shell carbon, mango shells carbon, palmyra endocarps carbon, palmyra male inflorescence carbon, maize shells carbon (N.V.V.S. Prasad, 2004). Some of these methods are cost effective and shows different adsorption properties and need scientific knowledge and any method does not give better results towards house 
hold levels. So an experimental defluoridation technique with mimosideae fruit carbons for house hold level has been developed.

Mimosideae is one of the large family containing more than 2000 plants in plant kingdom and having some medicinal and commercially valuable plants. In such plants highly abundantly available mostly in Asian countries like India, Enterolobium saman (Malasian oaks) Prosofis juliflora trees are very important towards firewood in developing countries. So large availability of these tree fruits were selected for defluoridation study.

\section{MATERIALS AND METHODS}

\subsection{Materials and experimental methods}

Dry fruits of mimosideae plants were collected in bulk, washed, dried, cut into small pieces and carbonised at $673 \mathrm{~K}$, sieved in to $45 \mu$ in a mechanical seiver, pyrolised and steam digested (at $873 \mathrm{~K})$. The carbonized material was treated with $2.5 \times 10^{-1} \mathrm{M}$ nitric acid for the removal of contaminants, followed by several washes with double distilled water and thermally activated in an air oven $393 \mathrm{~K}$ for 24 hours. Double distilled water was used for all experiments.

Elemental analysis of powdered carbonaceous samples was carried out by using Brookies S4 Pioneer energy dispersive X-ray fluorescence spectrometer.

Fluoride concentrations were determined colorimetrically by UV-Visible spectrophotometer (Chemito, model No UV - 2600). Elico LI 127 model digital $\mathrm{pH}$ meter is used for the determination of $\mathrm{pH}$ and Systronics 304 digital conductivity meter was used for measuring the electrical conductivity. The various physico-chemical parameters such as bulk density, moister content, surface area, $\mathrm{pH}$ and electrical conductivity of carbon treated water were studied by standard procedure (Kinniberg et al., 1975). Commercial activated carbon was supplied by Ranbaxy laboratories Ltd., India.

\subsection{Batch experiments}

$100 \mathrm{ml}$ of $5 \mathrm{mg} / \mathrm{L}$ of fluoride solution and $500 \mathrm{mg}$ prepared carbons were taken in beaker. The resulting solution was agitated on Remi Shaker at $240 \mathrm{rpm}$ for $30 \mathrm{~min}$. at room temperature $303 \pm 1 \mathrm{~K}$. After equilibration the solution was filtered through whatman No42 filter paper and filtrate was analysed for fluoride content by SPADNS method (APHA, 2000).

\section{RESULTS AND DISCUSSIONS}

\subsection{Physical Characteristics}

The physico-chemical parameters such as surface area of ESC is $9439.02 \AA$, PJC is 9047.42 $\AA \mathrm{CAC}$ is $8505.93 \AA$ and $\mathrm{pH}(7.08,7.16,7.54)$, electrical conductivity $(87,102,56 \mu . \mathrm{ohms})$, acid soluble matter $(0.042,0.0015,2.75 \%)$, water soluble matter $(0.22,0.123,0.82 \%)$, color (no color), surface tension (no change) and density (no change) of ESC,PJC and CAC treated water have been determined. The surface area of ESC and PJC are higher than CAC, so higher adsorption capacity will be expected from ESC and PJC all physico-chemical parameters of carbon treated water were within the permissible limits (WHO,1991). Semi quantitative and qualitative analysis was carried out in order to find out the composition of the adsorbents by X- ray fluorescence spectrometer. Figure 1 shows the presences of different elements in micro levels and results were given in Table 1. 
Table 1 Composition (wt \%) of adsorbent materials

\begin{tabular}{|c|c|c|c|c|c|}
\hline \multicolumn{3}{|c|}{ S.No Composition Atomic No } & \multirow{2}{*}{$\frac{\text { CAC }}{0}$} & \multirow{2}{*}{$\begin{array}{c}\text { ESC } \\
0.059\end{array}$} & \multirow{2}{*}{$\frac{\text { PJC }}{0}$} \\
\hline 1 & $\mathrm{Al}$ & 13 & & & \\
\hline 2 & As & 33 & 0 & 0.0025 & 0 \\
\hline 3 & $\mathrm{C}$ & 6 & 90.3 & 80.3 & 81.2 \\
\hline 4 & $\mathrm{Ca}$ & 20 & 2.94 & 0.1635 & 0.11 \\
\hline 5 & $\mathrm{Cl}$ & 17 & 0 & 0.0428 & 0.035 \\
\hline 6 & $\mathrm{Cu}$ & 29 & 0.232 & 0 & 0 \\
\hline 7 & $\mathrm{Fe}$ & 26 & 0.197 & 0.007093 & 0 \\
\hline 8 & K & 19 & 0.29 & 0.213 & 0.0582 \\
\hline 9 & $\mathrm{Mg}$ & 12 & 5.37 & 0.00952 & 0.0031 \\
\hline 10 & $\mathrm{Mn}$ & 25 & 0 & 0.00344 & 0 \\
\hline 11 & $\mathrm{Na}$ & 13 & 0 & 0 & 0.0019 \\
\hline 12 & $\mathrm{O}$ & 8 & 0 & 19.0 & 18.5 \\
\hline 13 & $\mathrm{P}$ & 15 & 0 & 0.158 & 0.0879 \\
\hline 14 & $\mathrm{Re}$ & 75 & 0 & 0 & 0.0033 \\
\hline 15 & $\mathrm{Rh}$ & 45 & 0.14 & 0.00031 & 0.0013 \\
\hline 16 & $\mathrm{~S}$ & 16 & 0 & 0.034 & 0.0231 \\
\hline 17 & $\mathrm{Si}$ & 14 & 0 & 0.0398 & 0 \\
\hline 18 & $\mathrm{Ti}$ & 22 & 0 & 0.00254 & 0 \\
\hline
\end{tabular}

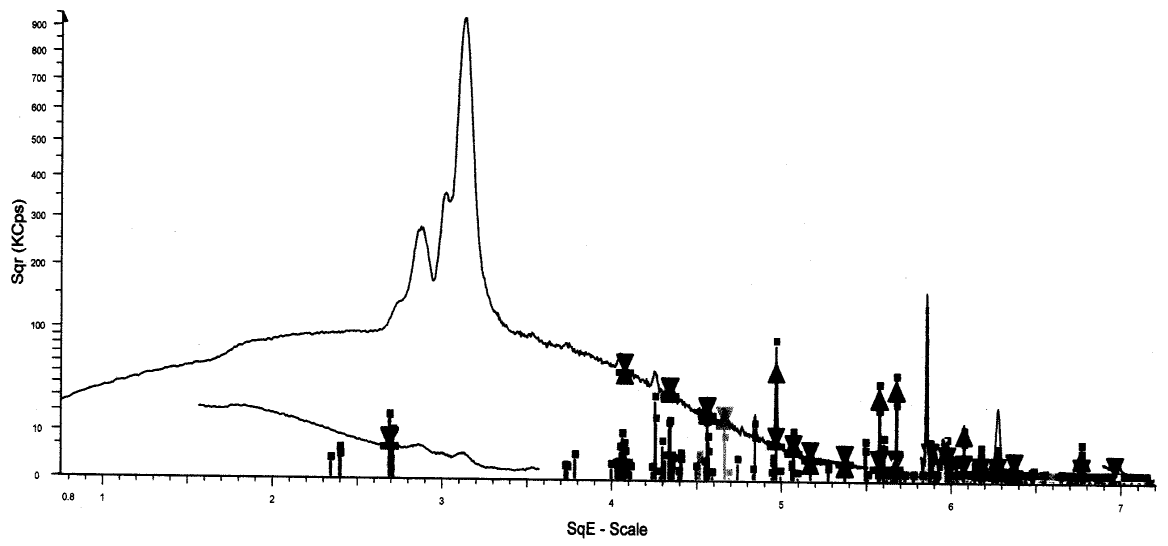

(A)

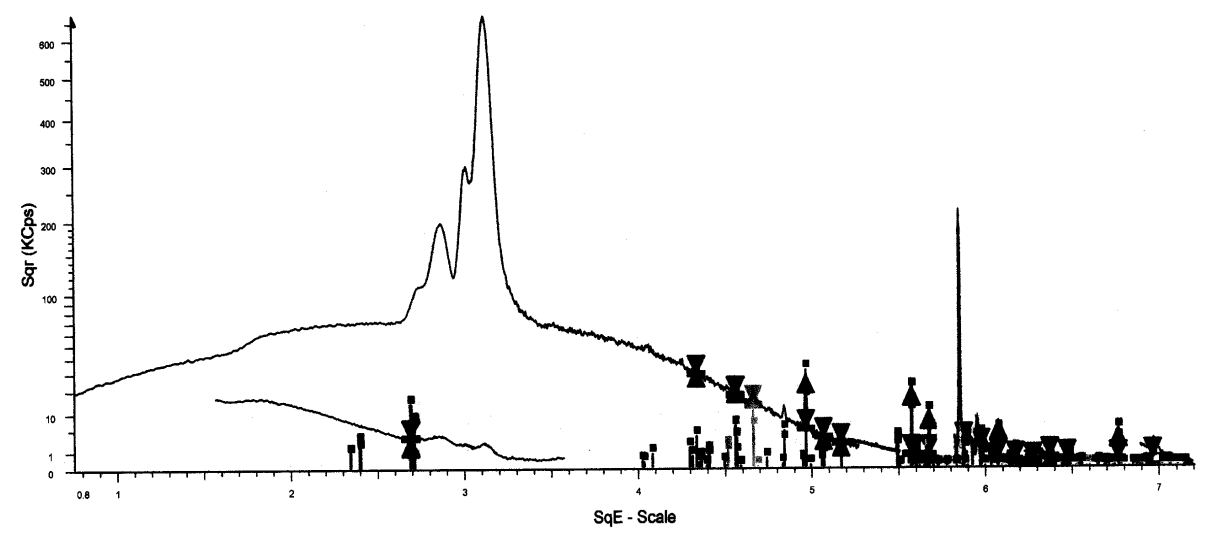

(B) 


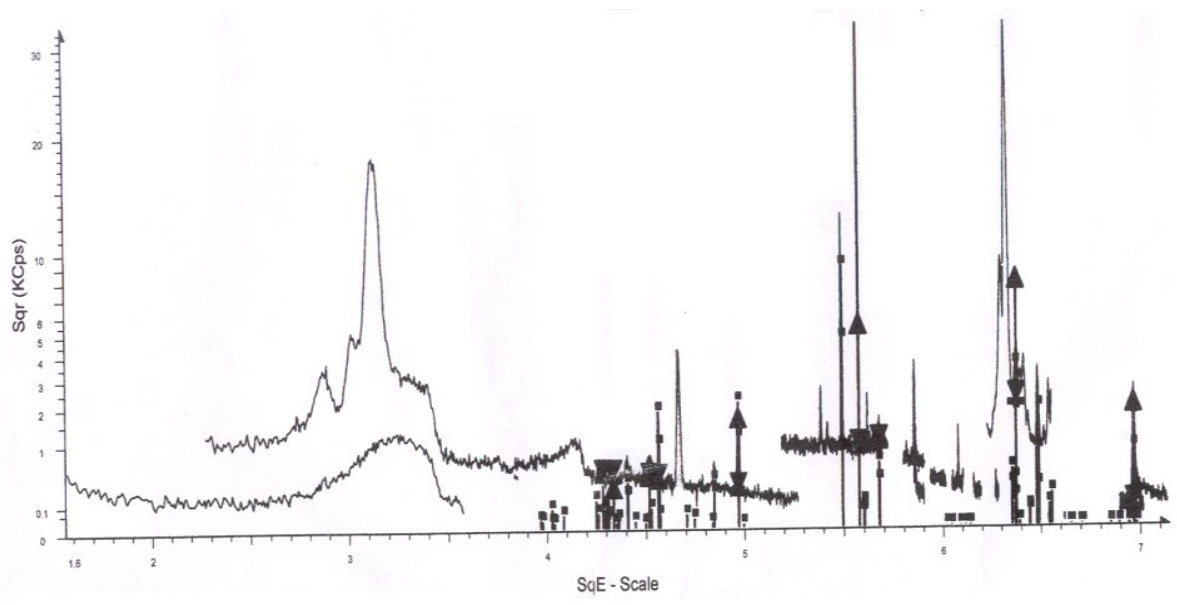

(C)

Fig.1. XRF patterns of adsorbents. (A) ESC (B) PJC (C) CAC

\subsection{Batch experiments}

Successful application of the fluoride adsorption technique demands innovation of cheap, non-toxic easily and locally available bio adsorbents. Knowledge of the optional conditions would herald a better design and modeling process. Thus the effect of some major factors like initial $\mathrm{pH}$ of fluoride solution, initial fluoride ion concentration, adsorbent dose, stirring time and particle size of the adsorbent. The concentration of fluoride ions by the up take of adsorbent materials was investigated from the kinetics view point. Adsorption studies were performed by batch technique to obtained the rate and equilibrium data. All the experiments were carried out at room temperature $(303 \pm 1 \mathrm{~K})$ by maintaining the optimum conditions (Table 2 ).

Table 2 Characteristics of the experimental system (Optimum conditions).

\begin{tabular}{cccccc}
\hline Parameter & Time.(min.) & $\begin{array}{c}\text { Conc. } \\
(\mathrm{mg} / \mathrm{L})\end{array}$ & Dose $(\mathrm{g})$. & $\mathrm{pH}$. & Particle size $(\mu)$. \\
\hline Time $(\mathrm{min})$. & $5-120$. & 5 & 4 & 7 & Mixed \\
Conc. $(\mathrm{mg} / \mathrm{L})$ & 40 & $1-7$ & - do- & - do- & -do- \\
Dose $(\mathrm{g})$ & - do- & 5 & $0.5-7.0$ & - do- & -do- \\
pH & - do- & - do- & 4 & $5-9$ & -do- \\
Particle size $(\mu)$ & -do- & - do- & - do- & - do- & $45-150$ \\
\hline
\end{tabular}

\subsection{Effect of $p H$}

The $\mathrm{pH}$ of the aqueous solution is a controlling factor in the adsorption process. Thus, the role of hydrogen ion concentration was examined at $\mathrm{pH}$ values of 5 to 9 (Figure 2). This was adjusted by adding $0.1 \mathrm{~N} \mathrm{HCl}$ solution and $0.1 \mathrm{M} \mathrm{NaOH}$ solution with $5 \mathrm{mg} / \mathrm{L}$ of fluoride solution.

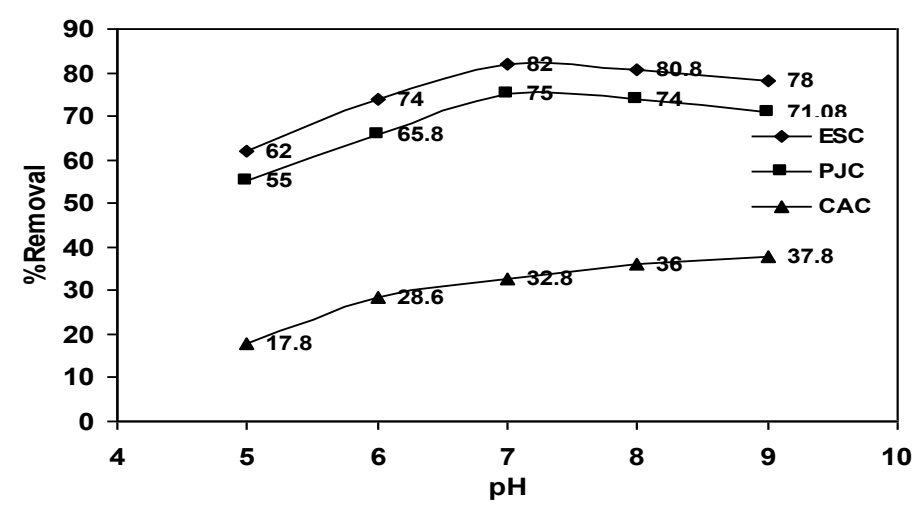

Fig.2. Effect of $\mathrm{pH}$ on fluoride adsorption on adsorbents. (At optimum conditions) 
Results were indicates the removal of fluoride ions in neutral $\mathrm{pH}$ of the solution. This was investigated as $82 \%$ for $\mathrm{ESC}, 75 \%$ for $\mathrm{PJC}$ at $\mathrm{pH} 7.0$ and for $\mathrm{CAC}$ maximum adsorption is $37.8 \%$ at $\mathrm{pH}$ 9.0. In this case the result may be due to neutralization of the negative charges at the surfaces of the treated biosorbent by greater hydrogen ion concentration at lower $\mathrm{pH}$ values. This reduces hindrance to diffusion of the negatively charged fluoride ions on to the increased active surface of treated biosorbents (A.V. Jamode et al.2004 and Bhargava et al.1991).

\subsection{Effect of contact time}

It was found that the removal of fluoride ions increases with increases in stirring time to some extent. Further increase in contact time does not increase the uptake due to deposition of fluoride ions on the available adsorption sites on adsorbent materials. Preliminary investigations on the up take of fluoride ions on the adsorbent material at their optimum $\mathrm{pH}$ values indicate that the process was quite rapid. Typically, $81 \%$ for ESC, $71.6 \%$ for PJC and for CAC is $35.8 \%$ (Figure 3) of adsorption occurs within $40 \mathrm{~min}$ at optimum conditions for treated biosorbents. This initial rapid adsorption subsequently gives way to a very slow approach to equilibrium and saturation is reached in 40 to $60 \mathrm{~min}$. for further optimization of other parameters, this contact time was considered as the equilibrium time.

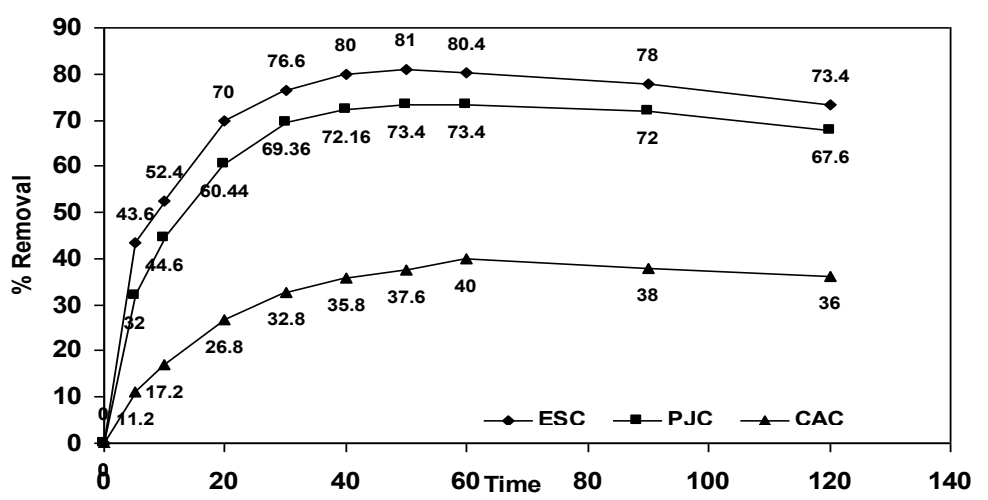

Fig.3. Effect of stirring time on percent removal of fluoride by adsorption

\subsection{Effect of adsorbent dose}

From Figure 4, it was concluded that the removal of fluoride ions increases with increase in the amount of adsorbent. The amount of dose was varied between 1.0 to $7 \mathrm{mg} / \mathrm{L}$ in aqueous solution at their optimum conditions. Results showed that biosorbents ESC, PJC and CAC shows maximum adsorption up to $5 \mathrm{mg} / \mathrm{L}$, after that removal capacity is very low, so $5.0 \mathrm{mg} / \mathrm{L}$ was fixed for further studies as optimum condition.

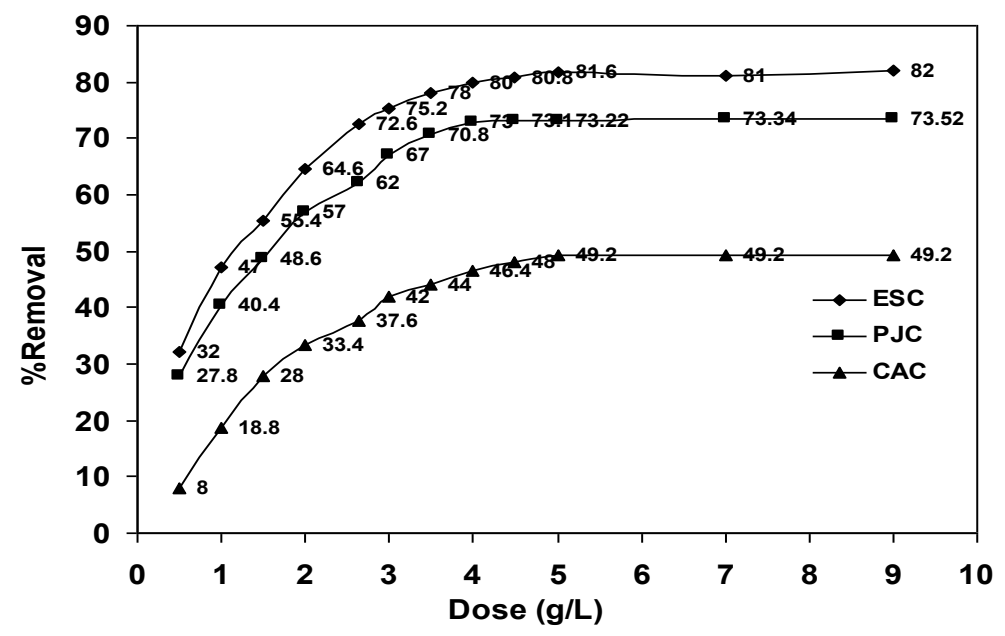

Fig.4. Effect of Dose on percent removal of fluoride by adsorption 


\subsection{Effect of initial fluoride concentration}

For a strictly adsorptive reaction, in the optimized period of contact, the rate varies directly with the concentration of adsorbate. The capacity of the adsorbent materials gets exhausted sharply with increase in initial fluoride ion concentration (Figure 5). The adsorption capacity of treated biosorbents was systematically studied by varying the initial concentration of fluoride ions between $1-7 \mathrm{mg} / \mathrm{L}$. Treated ESC and PJC seen fairly active in reducing fluoride ions 92 to $71.42 \%$ where as in CAC it was 60 to $30.2 \%$.

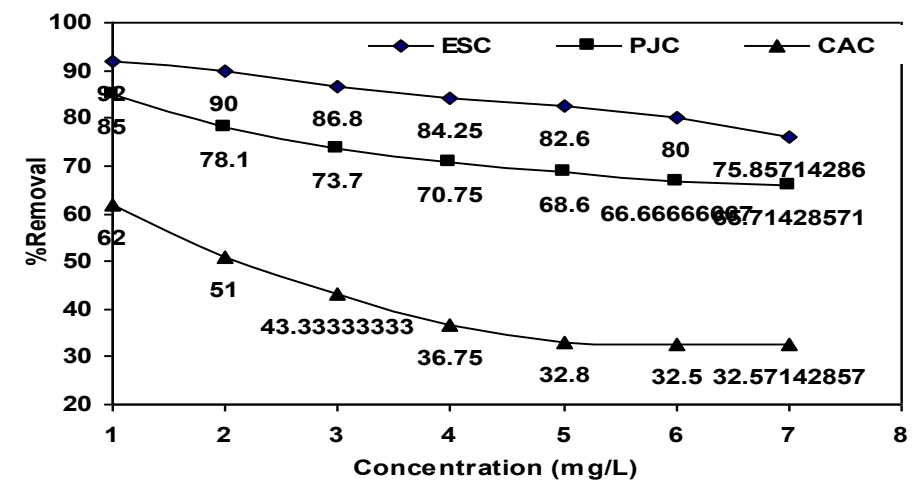

Fig.5. Percent removal of fluoride by adsorption on adsorbents

\subsection{Effect of adsorbent particle size}

Experiments were conducted to evaluate the influence of particle size by varying $150 \mu$ to $45 \mu$, the results were given in Figure 6 . The up take of fluoride ions at different adsorbent particle sizes increased with decreased in adsorbents (ESC \& PJC) particle diameter. The presence of large number of smaller particles provides the sorption system with a larger surface area available for the fluoride ion removal and it also reduces the external mass transfer resistance (A.V.Jamode et al.,2004).This also gives some idea of rate limiting step of the adsorption process (N.Kannan et al.,2004).With the largest particle size shows poor $(68.8 \%)$ adsorption capacity where as higher values $(90.8 \%$ and $80.2 \%)$ for smaller particles in ESC and PJC respectively.

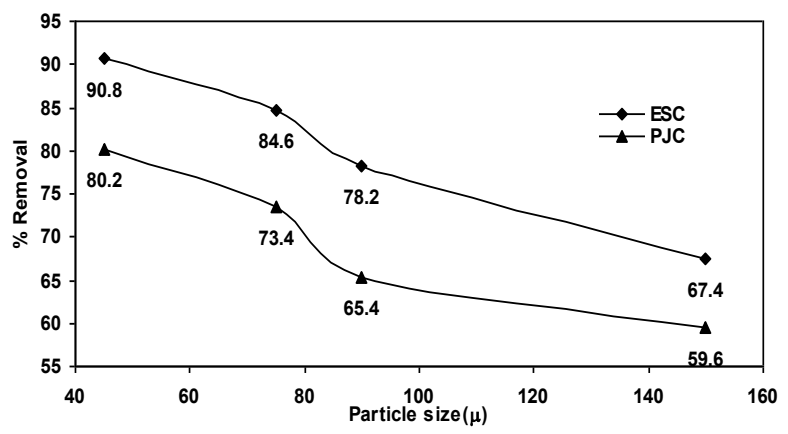

Fig.6. Variation of the amount of fluoride adsorbed with increasing the particle size

\subsection{Adsorption isotherm}

The application of adsorption isotherms has been of importance and significance in the water treatment by adsorption, as it provides an approximate estimation of mono-layer adsorption capacity of the adsorbent. The Equilibrium data for the removal of fluoride by adsorption on ESC, PJC and CAC at room temperature obtained from the effect of initial concentration of fluoride was fitted with the Freundlich and Longmuir adsorption isotherms (N.Kannan et al., 2001, 2002). This information is represented by the following equations:

Freundlich Isotherm:

$\log \left(\mathrm{C}_{\mathrm{i}} / \mathrm{C}_{\mathrm{e}}\right)=\log \mathrm{K}+(1 / \mathrm{n}) \log \mathrm{C}_{\mathrm{e}}$

Langmuir Isotherm:

$\left(\mathrm{C}_{\mathrm{e}} / \mathrm{q}_{\mathrm{e}}\right)=(1 / \mathrm{ab})+\left(\mathrm{C}_{\mathrm{e}} / \mathrm{a}\right)$ 
Where, $\mathrm{K}$ and $1 / \mathrm{n}$ are the measures of adsorption capacity and intensity of adsorption respectively, $\mathrm{q}_{\mathrm{e}}$ is the amount of fluoride adsorbed per unit weight of the adsorbent (in $\mathrm{mg} / \mathrm{g}$ ), $\mathrm{C}_{\mathrm{e}}$ is the equilibrium concentration of fluoride (in $\mathrm{mg} / \mathrm{g}$ ); ' $\mathrm{a}$ ' and ' $\mathrm{b}$ ' are Langmuir constants. The values of $\mathrm{K}$ and $1 / \mathrm{n}$ have been obtained from the linear correlations of $\log \mathrm{q}_{\mathrm{e}}$ against $\log \mathrm{C}_{\mathrm{e}}$ and the Langmuir constants have been also determined from the linear correlations of $\mathrm{C}_{e} / \mathrm{q}_{\mathrm{e}}$ against $\mathrm{C}_{\mathrm{e}}$. The isotherms (Figures7-8) parameters along with the correlation coefficients (r-values) for adsorbents are presented in Table 3. The observed linear relationships as evidenced by r-values close to unity confirm that these two adsorption isotherms are applicable.

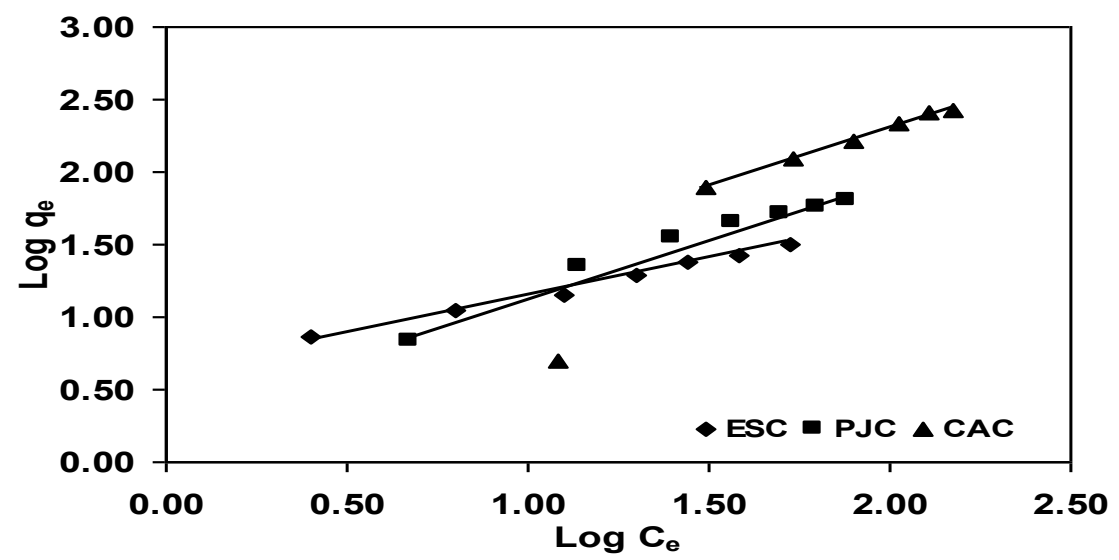

Fig.7. Calculation of Freundlich isotherm for the removal of fluoride by adsorption

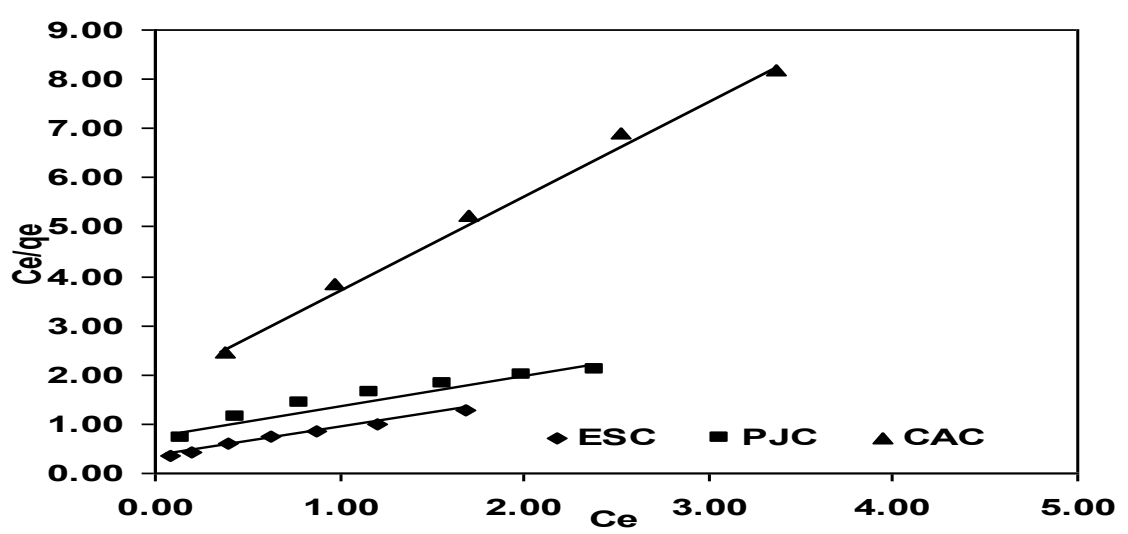

Fig.8. Calculation of Langmuir isotherm for the removal of fluoride by adsorption

The applicability of Langmuir isotherm model indicates the formation of monolayer coverage of adsorbate on outer surface of the adsorbent. Further, the essential characteristics of the Langmuir isotherm can be described by a separation factor $\mathrm{R}_{\mathrm{L}}$, which is defined by (Weber et al., 1974).

$\mathrm{R}_{\mathrm{L}}=1 /\left(1+\mathrm{bC}_{\mathrm{i}}\right)$

Where, $C_{i}$ is the initial concentration of fluoride (in $\mathrm{mg} / \mathrm{g}$ ) and ' $\mathrm{b}$ ' is the Langmuir constant (in $\mathrm{g} / \mathrm{L}$ ). The separation factor $\mathrm{R}_{\mathrm{L}}$ indicates favorable for all these low-cost adsorbents.

\subsection{Kinetics of the adsorption}

\subsubsection{Natarajan and Khalaf model}

The first order nature for the adsorption of fluoride were obtained by using the various first order kinetic equations Natarajan and Khalaf (N.Kannan et al 2001) have been employed;

Natarajan and Khalaf $=\log \left(\mathrm{C}_{\mathrm{o}} / \mathrm{C}_{\mathrm{t}}\right)=(\mathrm{k} / 2.303) \mathrm{t}$

Where $\mathrm{C}_{\mathrm{o}}, \mathrm{C}_{\mathrm{t}}$ and $\mathrm{C}_{\mathrm{e}}$ are the concentration of fluoride $(\mathrm{mg} / \mathrm{L})$ at time zero, at time $\mathrm{t}$, and $\mathrm{k}$ $\left(\min ^{-1}\right)$ is the rate constant. The values of $\log \left(\mathrm{C}_{\mathrm{i}} / \mathrm{C}_{\mathrm{e}}\right)$ and $\log (\%$ removal) (Figure 9) have been 
linearly correlated with time. The results of linear regression analysis (r-values) and the values rate constants are presented in Table 3. All the linear correlations have been found to be statistically significant (as evidenced by $\mathrm{r}$ values close to unity) at $95 \%$ confidence level and indicating the applicability of these kinetic equations and the first order nature of the adsorption process of fluoride on various adsorbents.

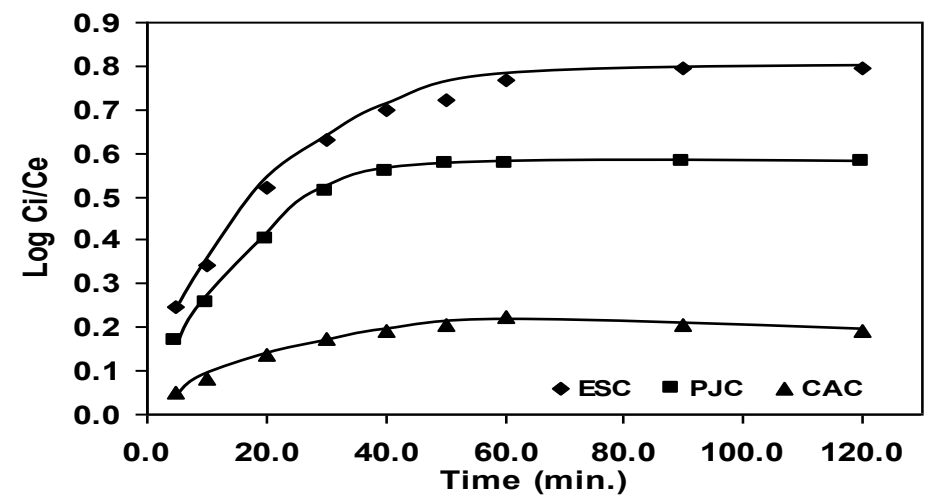

Fig.9. Calculation of Natarajan \& Khalaf equation for the removal of fluoride by adsorption

\subsubsection{Intraparticle diffusion model:}

In a rapidly stirred batch reactor, the adsorbate species are most probably transported from the bulk of the solution to the solid phase through Intraparticle diffusion which is often the rate limiting step in many sorption processes.

The model for intraparticle diffusion is:

$\mathrm{q}_{\mathrm{e}}=\mathrm{K}_{\mathrm{p}} \mathrm{t}_{1 / 2}+\mathrm{C}$

Where, $\mathrm{q}_{\mathrm{e}}$ is the amount of fluoride adsorbed per unit mass of the adsorbent (in $\mathrm{mg} / \mathrm{g}$ ) at time $t ; k_{p}$ and $C$ are respectively the intraparticle diffusion rate constant $\left(\mathrm{mg} / \mathrm{g} \cdot \mathrm{min}^{-1 / 2}\right)$ and the intercept. The values of amount of fluoride adsorbed have been correlated with the $t_{1 / 2}\left(\mathrm{~min}^{1 / 2}\right)$ for various adsorbents. This possibility has been established the linear correlation between $\log (\%$ removal) versus log (time) for the removal of fluoride by adsorption on activated carbons. This linear plot (Figure10) indicates the possibility of intra particle diffusion and also confirms the rate determining step. The calculated values (Table 3$)$ of Intraparticle diffusion rate constant $\left(\mathrm{K}_{\mathrm{p}}\right)$ indicate that the intraparticle diffusion process is more significant in PJC system than in ESC system. The values of intercept (C) give an idea of boundary layer thickness, i.e., the larger the intercept, the greater the boundary layer effect (N.V.V.S Prasad, 2004). The values of intercept decrease in the order $\mathrm{ESC}>\mathrm{PJC}>\mathrm{CAC}$.

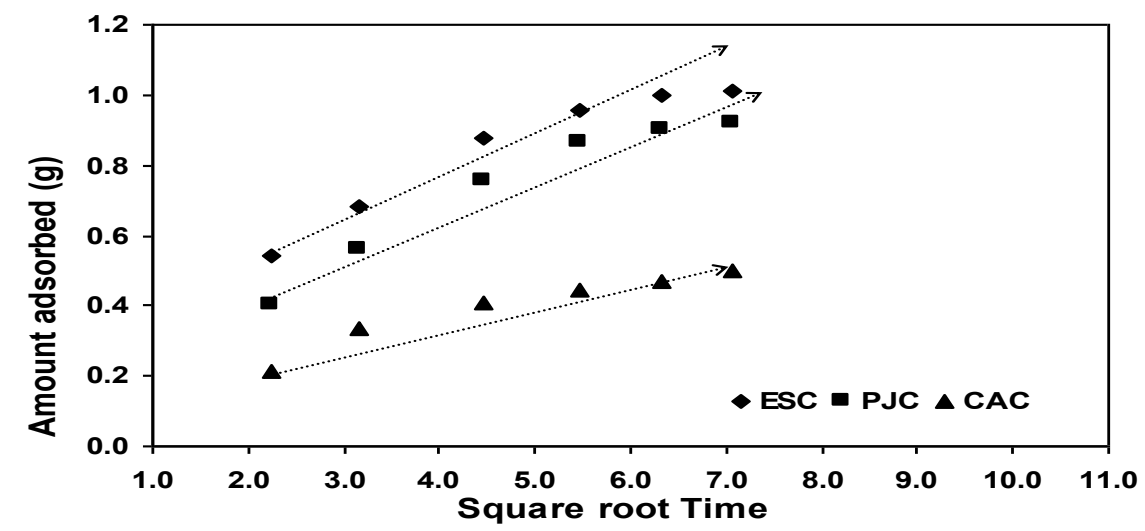

Fig. 10. Calculation of Intraparticle diffusion model for the removal of fluoride by adsorption 
Table 3 Statistical and empirical data estimated from isotherm and kinetic equations for removal of fluoride of fluoridated water.

\begin{tabular}{|c|c|c|c|}
\hline Isotherm Parameter & ESC & PJC & $\mathrm{CAC}$ \\
\hline \multicolumn{4}{|l|}{ Freundlich isotherm } \\
\hline $\log \mathrm{k}$ & 0.64933 & 0.36970 & 0.6425 \\
\hline $1 / \mathrm{n}$ & 0.48983 & 0.79475 & 1.48267 \\
\hline \multicolumn{4}{|c|}{ Langmuir isotherm } \\
\hline $\mathrm{R}$ & 0.99448 & 0.96164 & 0.51680 \\
\hline $\mathrm{a}(\mathrm{mg} / \mathrm{g})$ & 1.80025 & 1.71737 & 0.51874 \\
\hline $\mathrm{b}(\mathrm{g} / \mathrm{L})$ & 1.58709 & 0.69471 & 1.03069 \\
\hline $\mathrm{R}_{\mathrm{L}}$ & 0.11191 & 0.22353 & 0.16251 \\
\hline \multicolumn{4}{|c|}{ Natarajan \& Khalaf equation } \\
\hline $\mathrm{K}\left(\min ^{-1}\right)$ & 0.00436 & 0.00309 & 0.00113 \\
\hline $\mathrm{R}$ & 0.82269 & 0.74719 & 0.71806 \\
\hline \multicolumn{4}{|c|}{ Intraparticle diffusion model } \\
\hline $\mathrm{K}_{\mathrm{p}}\left(\mathrm{mg} . / \mathrm{g} \cdot \mathrm{min}^{-0.5}\right)$ & 0.05537 & 0.05606 & 0.02393 \\
\hline $\mathrm{C}$ & 0.56164 & 0.44115 & 0.26831 \\
\hline $\mathrm{R}$ & 0.86873 & 0.83402 & 0.75069 \\
\hline \multicolumn{4}{|c|}{ Log (\% Rem.)Vs Log (Time) } \\
\hline $\mathrm{K}\left(\right.$ time $\left.^{-1}\right)$ & 0.21169 & 0.26429 & 0.42424 \\
\hline $\mathrm{C}$ & 1.53408 & 1.39010 & 0.82504 \\
\hline $\mathrm{R}$ & 0.94367 & 0.95831 & 0.95831 \\
\hline
\end{tabular}

\section{REGENERATION STUDIES}

Fluoride loaded carbon regenerated with $1.0 \times 10^{-1} \mathrm{NaOH} \mathrm{mol} / 1, \mathrm{Na}_{2} \mathrm{CO}_{3}, \mathrm{KOH}$ and $1.0 \times 10^{-2}$ $\mathrm{H}_{2} \mathrm{SO}_{4} \mathrm{~mol} / 1$ solutions respectively. The system was operated at optimum conditions based on the batch experiment results. $50 \mathrm{ml}$ sample was taken from the effluent during regeneration and analysed for fluoride. Results reveal that in some alkali solutions regenerate fluoride rich carbons (ESC, PJC \& CAC) up to $72-70 \%$ while others up to $68-55 \%$. It was found that the adsorbent material has been successfully regenerated with alkali solutions.

\section{RECYCLING STUDIES}

It is an important aspect in the adsorption study especially when the low cost materials are used as adsorbents in potable water defluoridation studies. In the present water management study successfulness of adsorbent materials are depend on the further useful in continuous fluoride removal by adsorption. Fluoride loaded material has been recycled successfully for the adsorption of fluoride from aqueous media up to 4 cycles (Figure 11), after that fluoride removal capacity is poor and the concentration is above the permissible limit 1.5mg/1 (WHO...1991). But CAC is not reducing to permissible limit. So the prepared materials are better adsorbents at house hold level defluoridation. 


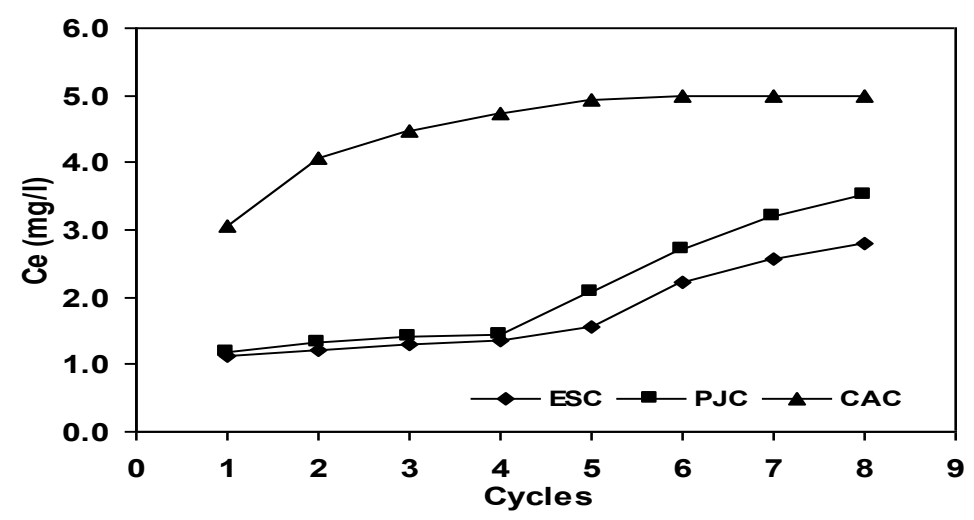

Fig.11. Recycling studies of various carbons in the removal of fluoride by adsorption.

\section{APPLICATIONS}

The suitability of the carbons for removing the fluoride from potable water was next investigated. Table 4 shows the characteristics of the potable water before and after defluoridation. From the results ESC effectively removes the fluoride to optimum level without disturbing the water quality parameters, but the fluoride removal capacity of CAC was very poor and does not reduce to optimum level concentration.

Table 4 Physico chemical analysis of potable water before and after defluoridation

\begin{tabular}{ccccc} 
& Before & \multicolumn{3}{c}{ After } \\
\hline Parameter & & ESC & PJC & CAC \\
pH & 7.52 & 7.56 & 7.49 & 7.48 \\
EC $(\mathrm{ms})$ & 1.229 & 1.321 & 1.302 & 1.321 \\
TDS & 556.5 & 526.42 & 528 & 556 \\
Turbidity & 0.5 & 0.2 & 0.2 & 0.2 \\
Salinity & 20.02 & 12.12 & 13.1 & 12.12 \\
Total hardness & 780 & 652 & 675 & 742 \\
Total Alkalinity & 485.62 & 480.68 & 480.68 & 480.68 \\
Fluoride & 2.56 & 1.02 & 1.18 & 1.98 \\
Chlorides & 238.56 & 240.2 & 235 & 240 \\
Nitrates & 2.3 & 2.1 & 2.2 & 2.3 \\
Phosphates & 0.314 & 0.31 & 0.32 & 0.32 \\
Sulphates & 42 & 43 & 42 & 42 \\
Sodium & 78.26 & 72.36 & 73.1 & 77.6 \\
Potassium & 2 & 1 & 2 & 2 \\
Calcium & 85 & 65 & 72 & 84 \\
Magnesium & 26 & 12 & 21 & 25 \\
Iron & 0.22 & 0.21 & 0.22 & 0.22 \\
\hline
\end{tabular}

\section{CONCLUSIONS}

The comparative study shows that ESC and PJC are very effective for the removal of fluoride from dilute aqueous solutions over a wide range of $\mathrm{pH}$ (5.0-9.0). The capacity of the carbon is superior to other carbons hitherto reported for the removal of fluoride from potable water. The carbon can be readily regenerated with number of solutions and can be reused. The carbon, possessed good bulk density and good attritional characteristics and, therefore, can find widespread use for defluoridation. 


\section{References}

[1]. APHA., Standard methods for examination of water and waste water., 2000. American Public Health Association, Washington DC, $18^{\text {th }}$ edn. 359-361.

[2]. Bhargava, D.S., Killidar, D.J., 2001. Batch studies of water defluoridation using fish bone charcoal. Res. J. Water process. Chem. Engrs. 26, 781-788.

[3]. Jamode, A.V., Jamode, V.S., Chandak, B.S., Rao, M., 2004. Evaluation of performance and kinetic parameters for defluoridation using Azadirachta Indica (Neem) leaves as low cost adsorbents. Pollution Research. 23(2), 239-250.

[4]. Jamode, A.V., Sapkalm, V.S., Jamode, V.S., 2004. Defluoridation of water using inexpensive adsorbents. J.Indian Inst.Sci., 84,163-171.

[5]. Kannan, N., Meenakshi Sundaram., 2001. Kinetics and mechanism of removal of methylene blue by adsorption - A comparative study. Dyes and Pigments.51, 25-40.

[6]. Kannan, N., Meenakshi Sundaram., 2002. Adsorption of Congo red on various activated carbons - A comparative study. Water Air Soil Poll. 138,289-305.

[7]. Kannan, N., Muthuraman., 2004. Studies on the removal of Xylenol orange and Bromocresol Purple by adsorption on activated char coal. Indian J.Env.Prot. 24 (11), 849 855.

[8]. Khare, S.K., Singh, A., Srivasthava., 1987. Mixed adsorbents for color removal from aqueous solution. Pertanika. 10 (3), $341-347$.

[9]. Kinniburg, D.G., Syer, J.K., Jockson, M.L., 1975.Specific adsorption of trace elements of calcium and strontium by hydroxides of iron and aluminium. Soil Sci. Soc., Am Proc., 39, $464-468$.

[10]. Prasad, N.V.V.S., Defluoridation of potable water with low cost Adsorbents, Ph.D. dissertation., 2003. Department of Chemistry, Nuzvid, Andhra Pradesh, India, Nagarjuna University.

[11]. WHO Guidelines for drinking water quality; Geneva., 1985. Drinking water quality control in small community supplies. 8-121.

[12]. Weber, T.W., R.K.Chakravorthi., 1974. Pore and solid diffusion models for fixed bed adsorbents. J.Ind.Chem.Eng. 22,228-238. 